\title{
Single nucleotide polymorphism (SNP) genotyping as basis for developing a PCR-based marker highly diagnostic for potato varieties with high resistance to Globodera pallida pathotype Pa2/3
}

\author{
Amirali Sattarzadeh · Ute Achenbach · Jens Lübeck · Josef Strahwald • \\ Eckhard Tacke · Hans-Reinhard Hofferbert · Tamara Rothsteyn • \\ Christiane Gebhardt
}

Received: 14 March 2006/ Accepted: 20 May 2006/Published online: 5 October 2006

(C) Springer Science+Business Media B.V. 2006

\begin{abstract}
Globodera pallida is a parasitic root cyst nematode of potato, which causes reduction of crop yield and quality in infested fields. Field populations of $G$. pallida containing mixtures of pathotypes $\mathrm{Pa} 2$ and $\mathrm{Pa} 3(\mathrm{~Pa} 2 / 3)$ are currently most relevant for potato cultivation in middle Europe. Genes for resistance to G. pallida have been introgressed into the cultivated potato gene pool from the wild, tuber bearing Solanum species $S$. spegazzinii and S. vernei. Selection of resistant genotypes in breeding programs is hampered by the fact that the phenotypic evaluation of resistance to G. pallida is time consuming, costly and often ambiguous. DNA-based
\end{abstract}

Amirali Sattarzadeh and Ute Achenbach contributed equally to the work.

A. Sattarzadeh - U. Achenbach - T. Rothsteyn ·

C. Gebhardt $(\bowtie)$

Max-Planck Institut für Züchtungsforschung, Carl von

Linné Weg 10, 50829 Köln, Germany

e-mail: gebhardt@mpiz-koeln.mpg.de

J. Lübeck · J. Strahwald

SaKa-Ragis Pflanzenzucht GbR, 24340 Windeby,

Germany

E. Tacke

Bioplant GmbH, 29574 Ebstorf, Germany

H.-R. Hofferbert

Böhm-Nordkartoffel Agrarproduktion GbR, 21337

Lüneburg, Germany markers diagnostic for resistance to $G$. pallida would facilitate the development of resistant varieties. A tetraploid $F_{1}$ hybrid family SR-Gpa segregating for quantitative resistance to G. pallida was developed and evaluated for resistance to G. pallida population 'Chavornay'. Two subpopulations of 30 highly resistant and 30 susceptible individuals were selected and genotyped for 96 single nucleotide polymorphism (SNP) markers tagging 12 genomic regions on 10 potato chromosomes. Seven SNPs were found significantly linked to the nematode resistance, which were all located within a resistance hotspot' on potato chromosome V. A haplotype model for these seven SNPs was deduced from the SNP patterns observed in the SR-Gpa family. A PCR assay 'HC' was developed, which specifically detected the SNP haplotype $c$ that was linked with high levels of nematode resistance. The HC marker was only found in accessions of $S$. vernei. Screening with the HC marker 34 potato varieties resistant to $G$. pallida pathotypes $\mathrm{Pa} 2$ and/or $\mathrm{Pa} 3$ and 22 susceptible varieties demonstrated that the HC marker was highly diagnostic for presence of high levels of resistance to G. pallida pathotype $\mathrm{Pa} 2 / \mathrm{Pa} 3$.

Keywords Potato $\cdot$ Globodera pallida $\cdot$ Root cyst nematodes $\cdot$ Single nucleotide polymorphism (SNP) - Diagnostic marker $\cdot$ Haplotype 


\section{Introduction}

Two closely related root cyst nematode species, Globodera rostochiensis and Globodera pallida, are the most damaging parasitic nematodes in potato cultivation (Evans and Trudgill 1992). Control by nematicides and crop rotation is difficult, due to the high toxicity of nematicides to the environment and the long survival rate of the cysts in the soil. Therefore, high levels of genetic resistance to nematodes are an important character in breeding new potato varieties. This breeding goal has been successfully achieved for resistance to Globodera rostochiensis by introgression of major genes for resistance from S. tuberosum ssp andigena, S. spegazzinii and S. vernei (Ross 1986; Phillips 1994). The wide spread cultivation of varieties with resistance to G. rostochiensis favored however the multiplication of pathotypes of G. pallida, which gradually overcome these resistance genes. Resistance to G. pallida has been identified in the same Solanum species as resistance to G. rostochiensis, and accessions of $S$. vernei have mainly been used in variety breeding in the Netherlands and Germany (Ross 1986). Resistance to nematodes is assessed by the inoculation of test plants with a defined number of cysts or by planting in nematode infested soil. The cysts newly formed after 46 weeks post inoculation are collected and counted. Resistance to G. pallida appears quantitative and its phenotypic assessment is complicated by the fact that it depends not only from the genotype of the potato plant tested but also from the nematode population used for inoculation. Three pathotypes $\mathrm{Pa} 1, \mathrm{~Pa} 2$ and $\mathrm{Pa} 3$ of G. pallida have been distinguished based on differentials (Kort et al. 1977). G. pallida field populations are however not uniform with respect to pathotype composition. Populations containing mixtures of pathotypes $\mathrm{Pa} 2$ and $\mathrm{Pa} 3(\mathrm{~Pa} 2 / 3)$ are currently the most relevant for potato cultivation in middle Europe. The phenotypic evaluation of resistance to G. pallida is time consuming, costly and often ambiguous. The availability of DNA-based markers, which are easy to score, cost effective and diagnostic for resistance to G. pallida in wide germplasm pools, would reduce the need for resistance testing during variety development.
A prerequisite for developing such markers is the genetic dissection of the factors conferring resistance to $G$. pallida. A number of QTL (quantitative trait locus) mapping experiments for resistance to $G$. pallida have been performed in different, mostly diploid genetic backgrounds (Kreike et al. 1994; Bradshaw et al. 1998; Rouppe van der Voort et al. 1998, 2000; Bryan et al. 2002, 2004; Caromel et al. 2003, 2005). The major gene Gpa2 for resistance to G. pallida pathotype $\mathrm{Pa} 2$ on chromosome XII has been cloned and shown to be a member of the NB (nucleotide binding) LRR (leucine-rich-repeat) gene family, to which most known plant genes for pathogen resistance belong (van der Vossen et al. 2000). All QTL mapping studies for $G$. pallida resistance revealed one QRL (quantitative resistance locus) of major effect accompanied by few additional QRL of minor effect. The most prominent and reproducible QRL is located on potato chromosome $\mathrm{V}$ in a genomic region flanked by RFLP markers GP179 and GP21. A number of qualitative and quantitative resistance factors to various pathogens maps to this region as well as NB-LRR type genes (reviewed in Gebhardt and Valkonen 2001, https: //www.gabi.rzpd.de/projects/Pomamo/). Other QRL with large effects were detected on chromosomes IV, IX and XI. RFLP (restriction fragment length polymorphism), AFLP (amplified fragment length polymorphism) SSR (simple sequence repeat) and other PCR-based markers linked to QTL for resistance to G. pallida are available in abundance from these mapping experiments. However, a diagnostic value of a DNA marker beyond a particular QTL mapping population has been demonstrated only for the marker SPUD1636 linked to the major QRL on chromosome V (Bryan et al. 2002). In this case, an allele specific, 226 bp amplicon was found only in accessions of $S$. vernei and in some highly resistant breeding lines that have $S$. vernei as source of resistance to G. pallida in their pedigree (Bryan et al. 2002).

Single nucleotide polymorphism (SNP) markers have been identified in potato, which tag most of the genomic regions known to harbor genes for qualitative and/or quantitative resistance to various pathogens, among others resistance to $G$. pallida. Most of these SNP markers are derived 
from end sequences of potato BAC (bacterial artificial chromosome) insertions, which contain one or more NB-LRR type genes (Rickert et al. 2003). Due to the high degree of intraspecific DNA polymorphism in potato, comparative sequencing of specific amplicons generated from genomic DNA of different genotypes allows the simultaneous scoring of several SNP markers in a sequence of 200-500 bp. In addition, the sequence trace files can be evaluated at heterozygous SNP loci for the three possible allele dosages in tetraploid genotypes (3:1, 2:2 and 1:3) (Rickert et al. 2003). Taking advantage on one hand of the current knowledge of 'resistance hot spots' in the potato genome and on the other hand of SNP markers linked to them, we selectively genotyped resistance-linked SNP markers in two subpopulations of highly resistant and susceptible individuals of a tetraploid $\mathrm{F}_{1}$ family, which segregated for quantitative resistance to $G$. pallida. We identified SNP markers linked to a major resistance locus and used the SNP information to develop a haplotype specific PCR assay, which we show to be highly diagnostic for presence of high $\mathrm{Pa} 2 / 3$ resistance to $G$. pallida that has been introgressed in modern potato varieties from Solanum vernei.

\section{Materials and methods}

Plant material

The $F_{1}$ family Gpa-SR was generated by crossing the tetraploid breeding clones SR6 and SR5. SR6 was resistant to Globodera pallida pathotypes $\mathrm{Pa} 2$ and Pa3 and SR5 was susceptible. Of 250 seedlings grown in the greenhouse and assessed for general plant vigor, 20 plants were discarded. The remaining 230 genotypes were tested for resistance to $G$. pallida (one replication per genotype). Based on the first resistance test, 200 genotypes were retained and propagated the following year in the field at Windeby, Germany, under the same phytosanitary conditions as used for seed potatoes. The 200 genotypes were tested a second time for resistance to G. pallida (two replications per genotype). Based on the results of the two rounds of testing, 30 highly resistant and 30 highly susceptible genotypes were selected, which were propagated a third year and tested a third time for resistance to G. pallida (four replications per genotype). Based on a total of seven resistance tests, the average cyst counts were between zero and one for the highly resistant genotypes, and 22 cysts or more in the susceptible genotypes.

Thirty four varieties with resistance to G. pallida pathotypes $\mathrm{Pa} 2$ and/or $\mathrm{Pa} 3$ (Table 1) were obtained from Saka-Ragis Pflanzenzucht, Böhm-Nordkartoffel Agrarproduktion (BNA), Bavaria Saat (by courtesy of A. von Zwehl), HZPC Holland B.V., Averis Seeds B.V.and B.F. Leestemaker \& A. Smid (by courtesy of Jan Draaistra). DNA of 21 susceptible varieties was available (Gebhardt et al. 2004) from the collection maintained by the IPK potato germplasm bank at Groß-Lüsewitz (Germany). S. vernei clone 62-33-3 (Ross 1986) and the interspecific hybrid clone AM78.3778 (Rouppe van der Voort et al. 1998) were kindly provided by Björn Niere (Institute for Nematology, BBA Münster, Germany). Clone AM78.3778 has been originally provided by Richard Janssen.

DNA of the following Solanum species was available (Gebhardt et al. 2004); the number of accessions per species is given in parenthesis: S. acaule (3), S. alandiae (3), S. andigena (3), S. berthaultii (3), S. brevicaule (3), S. bukasovii (3), S. canasense (3), S. chacoense (3), S. demissum (3), S. dulcamara (1), S. etuberosum (2), S. gourlayi (3), S. hondelmannii (2), S. kurtzianum (3), S. leptophyes (3), S. lignicaule (1), S. maglia (1), S. megistacrolobum (2), S. microdontum (3), S. morelliforme (1), S. nigrum (1), S. neorossii (1), S. oplocense (3), S. phureja (3), S. pinnatisectum (1), S. sparsipilum (3), S. spegazzinii (3), S. stenotomum (3), S. stoloniferum (3), S. vernei (3), S. verrucosum (3). Accession numbers are available from the authors upon request.

\section{Assessment of resistance to G. pallida}

The genotypes of the Gpa-SR population were tested for resistance to G. pallida at the 'Landesamt für Landwirtschaft, Lebensmittelsicherheit und 
Table 1 Population test of markers HC, BA213c14t7-snp139, BA213c14t7-snp274 and SPUD1636 (Bryan et al. 2002) in varieties susceptible or resistant to $G$. pallida according to passport data

\begin{tabular}{|c|c|c|c|c|c|c|}
\hline Variety or clone & Breeder & $\begin{array}{l}\text { Resistance to } \\
\text { G. pallida pathotypes }{ }^{a}\end{array}$ & $\mathrm{HC}$ & snp139 & snp274 & SPUD1636 \\
\hline Angela & BNA & Susceptible & 0 & GGGG & AAAA & 0 \\
\hline Arkula & NORIKA & Susceptible & 0 & GGGG & AAAA & 0 \\
\hline Assia & Uniplanta & Susceptible & 0 & GGGG & AAAA & 0 \\
\hline Christa & KWS Saat (N: Ragis) & Susceptible & 0 & GGGG & AAAA & 0 \\
\hline Clarissa & BNA & Susceptible & 0 & GGAA & AAAA & 0 \\
\hline Desiree & Lange, W. & Susceptible & 0 & GGGG & AAAA & 0 \\
\hline Gloria & Saatzucht Soltau - Bergen & Susceptible & 0 & GGGG & AAAA & 0 \\
\hline Grata & Stader Saatzucht & Susceptible & 0 & GGGG & AAAA & 0 \\
\hline Hela & Vereinigte Saatzuchten & Susceptible & 0 & GGGG & AAAA & 0 \\
\hline Karat & NORIKA & Susceptible & 0 & GGAA & AAAA & 0 \\
\hline Karlena & NORIKA & Susceptible & 0 & GGGG & AAAA & 0 \\
\hline Koretta & NORIKA & Susceptible & 0 & GGGG & AAAA & 0 \\
\hline Lyra & BNA & Susceptible & 0 & GGGG & AAAA & 0 \\
\hline Maxilla & NORIKA & Susceptible & 0 & - & - & 0 \\
\hline Milva & Saatzucht Berding & Susceptible & 0 & GGGG & AAAA & Not tested \\
\hline Nora & BNA & Susceptible & 0 & GGGG & AAAA & 0 \\
\hline Selma & Bavaria Saat & Susceptible & 0 & AAAA & AAAA & 0 \\
\hline Tempora & BNA & Susceptible & 0 & GGAA & AAAA & 0 \\
\hline Toccata & BNA & Susceptible & 0 & GGAA & AAAA & 0 \\
\hline Tomensa & BNA & Susceptible & 0 & GGGG & AAAA & 0 \\
\hline Ute & Bavaria Saat & Susceptible & 0 & GGGG & AAAA & 0 \\
\hline Avano & Karna & $\mathrm{Pa} 2 / 3$ & 0 & AAAA & TTTT & 0 \\
\hline Avarna & Karna & $\mathrm{Pa} 2 / 3$ & 1 & AAAA & TTTT & 1 \\
\hline Aveka & Karna & $\mathrm{Pa} 2 / 3$ & 1 & GGAA & AATT & 1 \\
\hline Averia & Karna & $\mathrm{Pa} 2 / 3$ & 1 & AAAA & TTTT & 1 \\
\hline Aviala & Karna & $\mathrm{Pa} 2 / 3$ & 1 & AAAA & TTTT & 1 \\
\hline Brisant & Bavaria Saat & $\mathrm{Pa} 2 / 3$ & 1 & GGAA & AATT & 0 \\
\hline Festien & E.J. Feunekes & $\mathrm{Pa} 2 / 3$ & 1 & AAAA & AAAA & 1 \\
\hline Florijn & Hoiting & $\mathrm{Pa} 2 / 3$ & 1 & GGAA & ATTT & 0 \\
\hline Goya & J. Goosen & $\mathrm{Pa} 2 / 3$ & 1 & GAAA & ATTT & 0 \\
\hline Innovator & $\mathrm{HZPC}$ & $\mathrm{Pa} 2 / 3$ & 1 & AAAA & AAAT & 0 \\
\hline Karakter & Averis Saatzucht & $\mathrm{Pa} 2 / 3$ & $1 / 0^{b}$ & GGGG & AAAA & 0 \\
\hline Kartel & Karna & $\mathrm{Pa} 2 / 3$ & 1 & GAAA & ATTT & 1 \\
\hline Melanie & H.K.Kroeze \& G.M. Bunte & $\mathrm{Pa} 2 / 3$ & 1 & GGAA & AATT & 1 \\
\hline Menco & J.H. Mencke & $\mathrm{Pa} 2 / 3$ & 1 & GGAA & AATT & 1 \\
\hline Mercator & J.H. Mencke & $\mathrm{Pa} 2 / 3$ & 1 & GAAA & AATT & 0 \\
\hline Mercury & J.H. Mencke & $\mathrm{Pa} 2 / 3$ & 1 & GGAA & AATT & 0 \\
\hline Nomade & Matschaap Boerhave VOF & $\mathrm{Pa} 2 / 3$ & 1 & GGAA & AATT & 0 \\
\hline Seresta & R.H. Sloots & $\mathrm{Pa} 2 / 3$ & 1 & GAAA & ATTT & 1 \\
\hline Sjameto & Agrico & $\mathrm{Pa} 2 / 3$ & 1 & GGAA & AATT & 1 \\
\hline Stabilo & R.H. Sloots & $\mathrm{Pa} 2 / 3$ & 1 & AAAA & TTTT & 1 \\
\hline Starga & R.H. Sloots & $\mathrm{Pa} 2 / 3$ & 1 & GGAA & AATT & 1 \\
\hline Valiant & H. Kuipers & $\mathrm{Pa} 2 / 3$ & 1 & GAAA & TTTT & 1 \\
\hline AM78.3778 & & $\mathrm{Pa} 2 / 3$ & 1 & - & - & 1 \\
\hline Elles & B.F. Leestemaker \& A. Smid & $\mathrm{Pa} 2$ & 0 & GGGG & AAAA & 1 \\
\hline Feska & E.J. Feunekes & $\mathrm{Pa} 2$ & 0 & AAAA & AAAA & 0 \\
\hline Karida & Karna & $\mathrm{Pa} 2$ & 0 & GGGG & AAAA & 0 \\
\hline Karnico & Karna & $\mathrm{Pa} 2$ & 0 & GGGG & AAAA & 1 \\
\hline Producent & Kweekbedrijf Prummel & $\mathrm{Pa} 2$ & 0 & GGGG & AAAA & 0 \\
\hline S.vernei $62-33-3$ & & $\mathrm{~Pa} 2$ & 0 & - & - & 1 \\
\hline Sante & J. Vegter & $\mathrm{Pa} 1 / 2$ & 0 & GGGG & AAAA & 1 \\
\hline Amado & BNA & $\mathrm{Pa} 2 / 3$ partial & 1 & GGAA & AATT & 0 \\
\hline Kantara & Karna & $\mathrm{Pa} 2 / 3$ partial & 0 & - & - & 1 \\
\hline Kardent & Karna & $\mathrm{Pa} 2 / 3$ partial & 1 & GGGA & AATT & 1 \\
\hline
\end{tabular}


Table 1 continued

\begin{tabular}{llllll}
\hline Variety or clone & Breeder & $\begin{array}{l}\text { Resistance to } \\
\text { G. } \text { pallida } \text { pathotypes }{ }^{a}\end{array}$ & HC & snp139 & snp274 \\
\hline Katinka & Karna & Pa2/3 partial & 0 & AAAA & AAAA \\
Pallina & Bavaris Saat & Pa2/3 partial & 0 & GGGG & AAAA \\
\hline
\end{tabular}

a Resistance according to '81e rassenlijst Landbouwgewassen 2006' and 'Beschreibende Sortenliste Kartoffeln 2005'

${ }^{b}$ This variety gave inconsistent results for the HC marker in repeated tests

Fischerei Mecklenburg-Vorpommern' (Rostock, Germany) according to Behringer (1969) and Kort et al. (1977). The plants were inoculated with G. pallida population 'Chavornay'. The status of nematode resistance of the varieties was obtained from the variety lists of the Netherlands (81e rassenlijst Landbouwgewassen, 2006, ISSN 01687484) and Germany (Beschreibende Sortenliste Kartoffeln, 2005, ISSN 1430-9777).

\section{DNA isolation}

Young, healthy potato leaves were harvested, freeze dried and stored in air-tight containers at $-20^{\circ} \mathrm{C}$. Total genomic DNA was extracted from 0.3 to $0.4 \mathrm{~g}$ freeze dried leave material according to Bormann et al. (2004).

\section{SNP analysis}

Amplicons were generated from $50 \mathrm{ng}$ genomic DNA template each of the parents and $44 \mathrm{~F} 1$ individuals of population Gpa-SR in $30 \mu \mathrm{l}$ buffer (20 mM Tris- $\mathrm{HCl}, \quad$ pH 8.4, $2.5 \mathrm{mM}$ $\mathrm{MgCl}_{2}, 50 \mathrm{mM} \mathrm{KCl}$ ), including $200 \mathrm{nM}$ of each primer (Table 2), $100 \mu \mathrm{M}$ of $\mathrm{dNTP}$ and 0.4 1.0 units Taq DNA polymerase (Invitrogen Life Technologies, Freiburg, Germany). Standard cycling conditions were: $4 \mathrm{~min}$ initial denaturation at $94^{\circ} \mathrm{C}$, followed by 30 cycles of $1 \mathrm{~min}$ denaturation at $94^{\circ} \mathrm{C}, 1 \mathrm{~min}$ annealing at the appropriate $T_{\mathrm{m}}$ and $1 \mathrm{~min}$ extension at $72^{\circ} \mathrm{C}$. Reactions were finished by $8 \mathrm{~min}$ incubation at $72^{\circ} \mathrm{C}$. PCR products were examined for quality on ethidium bromide stained agarose gels. Before sequencing, $10 \mu \mathrm{l}$ PCR were incubated with 1 unit each of shrimp alkaline phosphatase (Amersham Pharmacia Biotech, Piscataway, USA) and exonuclease I (Invitrogen,
Carlsbath, USA) at $37^{\circ} \mathrm{C}$ for $30 \mathrm{~min}$ to remove non-incorporated dNTP's and residual singlestranded DNA. The enzymes were inactivated at $80^{\circ} \mathrm{C}$ for $15 \mathrm{~min}$. Amplicons were custom sequenced on $\mathrm{ABI} 377$ or $\mathrm{ABI} 3700$ sequencers (PE Biosystems, Foster City, CA, USA) at the Automated DNA Isolation and Sequencing (ADIS) unit of the Max-Planck Institute for Plant Breeding Research using the dideoxy chain-termination method and ABI PRISM Dye Terminator Cycle Sequencing Ready Reaction Kit. The electropherograms of the individual sequencing readouts (trace files) were visually inspected for segregating SNPs, which were detected by singular overlapping base calling peaks and for InDels, which were detected by overlapping sequencing readouts starting from defined nucleotide positions. SNPs were scored including the allele dosage, using both the Data Acquisition \& Data Analysis software DAx7.1 (Van Mierlo Software Consultancy) and manual scoring. The dosage of bi-allelic SNPs in heterozygous tetraploid genotypes $(3: 1,2: 2$ or $1: 3)$ was estimated from the height ratio of overlapping base calling peaks. The SNP scores and the categorized resistance scores (resistant or susceptible) of the $44 \mathrm{~F} 1$ individuals were arranged as tabular data. For each SNP marker segregating in the Gpa-SR population, between two and five genotype classes were observed, depending on the parental SNP configuration (for example AAAA, AAAG, AAGG, AGGG and GGGG). Pearson's $\chi^{2}$ test or Fisher's exact test were used to test the observed SNP genotype classes for significant deviation from the $\mathrm{H}_{0}$ hypothesis of equal frequency in the two phenotypic categories. Statistic tests were computed with SPSS software (SPSS $\mathrm{GmbH}$ Software, München, Germany). 
Allele specific PCR: haplotype $c$

Four primers were designed according to Sarkar and Sommer (1991), Lo et al. (1991) and Okimoto and Dodgston (1996). The two pairs of forward and reverse primers varied at the $3^{\prime}$ end for the BA87d17t3-snp212 alleles $C$ or $T$ and the snp444 alleles $G$ or $A$, respectively. A mismatch was introduced at the third nucleotide from the $3^{\prime}$ end (Okimoto and Dodgston 1996). All four possible primer combinations were tested for specific amplification of haplotype $c$ in the GpaSR family. The combination of the forward primer 5' ACACCACCTGTTTGATAAAAAACT $3^{\prime}$ with the reverse primer $5^{\prime}$ GCCTTACTTCCCTGCTGAAG 3' resulted in haplotype $c$

Table 2 Targeted loci, oligonucleotides used for PCR amplification and amplicon sequencing, and SNPs/InDels evaluated in resistant and susceptible $F_{1}$ plants of the Gpa-SR population

\begin{tabular}{|c|c|c|c|c|}
\hline Locus & LG & Oligonucleotide sequences $5^{\prime}-3^{\prime}$ & SNP number ${ }^{b}$ & InDel no. ${ }^{b}$ \\
\hline BA114i24t3 & I & $\begin{array}{l}\text { f-AGATCTGTGGATGTATAGGCGTAG }{ }^{a} \\
\text { r-CTAACACAATGTACTTGCAGGTG }\end{array}$ & $53,58,65,79$ & 93 \\
\hline St3.2 & II & $\begin{array}{l}\text { f-AGCAACTTAGGTCACAACCACAC }{ }^{a} \\
\text { r-TATCTTGAATTGTTTCCCTGCAGC }\end{array}$ & 52,162 & - \\
\hline St4cl & III & $\begin{array}{l}\text { f-AGCTTGTTTTGCGGGGAAAGTG }{ }^{a} \\
\text { r-AAATGGTCCAATTGTCACTTTATGC }\end{array}$ & $91,100,184,228,319$ & - \\
\hline BA70b11t7 & IV & $\begin{array}{l}\text { f-ATTCTTGAGATATTGTAACCCAAAC } \\
\text { r-TTTGAGGAACATATTAGACTTGTTG } \\
\text { fs-CTGATTGGAAGATGATCATAAG }{ }^{a}\end{array}$ & $105,127,166,181$ & - \\
\hline BA $87 \mathrm{~d} 17 \mathrm{t} 3$ & $\mathrm{~V}$ & $\begin{array}{l}\text { f-GTAGTACATCAACATACATTTTGCGG } \\
\text { r-CTCAGAATTCAGAGCTTCAACTGATG } \\
\text { fs-AACAGGCTTAATCCTCATCCGC }\end{array}$ & $109, \mathbf{2 1 2} * *^{*}, 222,383,384,444$ & - \\
\hline BA213c14t7 & $\mathrm{V}$ & $\begin{array}{l}\text { f-CAATTGATTCATTTTATGTAGCGAG } \\
\text { r-TCTTGACGCAAACCTCTGCGAG } \\
\text { fs-AAATATAAGATATAACTAAATTAA C }{ }^{a}\end{array}$ & $\begin{array}{l}96, \mathbf{1 3 9} * * *, \mathbf{1 5 2} * *, 214,218, \mathbf{2 3 6} * * \\
244,273, \mathbf{2 7 4} * * *, 284, \mathbf{2 8 7} * *, 289 \\
305,345,347\end{array}$ & - \\
\hline BA76o11t3 & $\mathrm{V}$ & $\begin{array}{l}\text { f-CAGGACATCAATATAAATACTGTTGC } \\
\text { r-CGTACGTATGAGGAGTCTGTATC } \\
\text { fs-CTATTTGTTCCTTCATGTGTCCTGGA }\end{array}$ & $336 * *$ & 363 \\
\hline BA132h9t3 & $\mathrm{V}$ & $\begin{array}{l}\text { f-GAAAGGCCATGTATATGCAGC } \\
\text { r-GCTATCAATATACTTATCTGCTC } \\
\text { rs-GTAACTTCTCTTCTTGAGGTGGAC }\end{array}$ & $178,224,260,272,287$ & - \\
\hline BA228g19t7 & VII & $\begin{array}{l}\text { f-GACTGTTGAGCCAACATGACTC } \\
\text { r-TGGAATTATGTTCAGCTTTGGTGA }{ }^{a}\end{array}$ & $\begin{array}{l}259,296,298,300,315,342,365 \\
369,372,373\end{array}$ & - \\
\hline BA73e $8 \mathrm{t} 3$ & VIII & $\begin{array}{l}\text { f-TGGCCTGAATTTGGATCAAATGG } \\
\text { r-GTTAATATCACTCATGGCACTATG } \\
\text { fs-CAAATAAAGGTATATGAAGATCTG }\end{array}$ & 107,117 & 124 \\
\hline BA261b9t7 & VIII & $\begin{array}{l}\text { f-TCAAAATTCACAGGGTGATTGGC }{ }^{a} \\
\text { r-ATGAAGTTACTCAGGCTAACAGG }\end{array}$ & $\begin{array}{l}115,128,144,147,175,209,229,256 \\
260,270\end{array}$ & - \\
\hline GP129 & IX & $\begin{array}{l}\text { f-GTGGTAGCAAAGTATTCATC } \\
\text { r-CGTTATCTGGACTCCTTTAG }\end{array}$ & $\begin{array}{l}55,94,148,149,161,178,190,196 \\
205,211\end{array}$ & - \\
\hline CP105 & $X$ & $\begin{array}{l}\text { f- GATGTTGTACAAGCTTGTCAAACC } \\
\text { r- CAAAATCAGGCCATTGTGAATGAG }\end{array}$ & $181,203,237,276,284$ & - \\
\hline BA81115t3 & $\mathrm{X}$ & $\begin{array}{l}\text { f- CTGTTGGGTCTTCCTATAAGTTGGG }{ }^{a} \\
\text { r- TGAAACCACTAАACATGACATTTTG }\end{array}$ & $93,114,162,218,235,239,241$ & - \\
\hline \multirow[t]{2}{*}{ NL27 } & XI & $\begin{array}{l}\text { f-TAGAGAGCATTAAGAAGCTGC } \\
\text { r-TTTTGCCTACTCCCGGCATG } \\
\text { rs-AGAGCAGTCCTCCATCCTTTCAC }\end{array}$ & $\begin{array}{l}212,214,329,420,424,425,438,439 \\
453,454\end{array}$ & - \\
\hline & & & Total 96 SNPs & 3 Indels \\
\hline
\end{tabular}

\footnotetext{
${ }^{a}$ Primer was used for sequencing the amplicons

${ }^{b}$ SNP and InDel numbering is according to the PoMaMo database (https://www.gabi.rzpd.de/projects/Pomamo/). New SNPs are numbered relative to known flanking SNPs

$c_{* * *}$ and $* *$ : unequal distribution of SNP alleles between resistant and susceptible genotypes, significant at $P<0.001$ and $P<0.01$, respectively
} 
specific amplification of a 276 bp DNA fragment using the following protocol: $50 \mathrm{ng}$ template DNA were amplified in $15 \mu \mathrm{l} \mathrm{PCR}-$ mix $(20 \mathrm{mM}$ Tris- $\mathrm{HCl}, \mathrm{pH} 8.4,1.5 \mathrm{mM} \mathrm{MgCl}_{2}, 50 \mathrm{mM} \mathrm{KCl}$, $100 \mu \mathrm{M}$ dNTP, $200 \mathrm{nM}$ of each primer, $2 \% \mathrm{v} / \mathrm{v}$ DMSO, 1 unit Taq DNA polymerase) and the PCR touchdown conditions: $5 \mathrm{~min}$ at $94^{\circ} \mathrm{C}$, one cycle of $1 \mathrm{~min}$ at $94^{\circ} \mathrm{C}, 1 \mathrm{~min}$ at $65^{\circ} \mathrm{C}$ and $1 \mathrm{~min}$ at $72^{\circ} \mathrm{C}$, six cycles of $30 \mathrm{~s}$ at $94^{\circ} \mathrm{C}, 30 \mathrm{~s}$ at $65^{\circ} \mathrm{C}$ decreasing the annealing temperature to $60^{\circ} \mathrm{C}$ by $1^{\circ} \mathrm{C}$ per cycle and $30 \mathrm{~s}$ at $72^{\circ} \mathrm{C}, 30$ cycles of $30 \mathrm{~s}$ at $94^{\circ} \mathrm{C}, 30 \mathrm{~s}$ at $60.5^{\circ} \mathrm{C}$ and $30 \mathrm{~s}$ at $72^{\circ} \mathrm{C}$, finally $5 \mathrm{~min}$ at $72^{\circ} \mathrm{C}$. PCR products were separated on standard agarose gels and visualized with ethidium bromide staining. The marker SPUD1636 was amplified as described (Bryan et al. 2002).

\section{Results}

Based on evaluating 230 individuals of the Gpa-SR family for resistance to $G$. pallida population 'Chavornay', the 30 most resistant and 30 highly susceptible $F_{1}$ individuals were selected for genotyping. Amplicons were generated at 15 loci (Table 2) from genomic DNA of parents SR5 and SR6, 22 resistant and 22 susceptible $F_{1}$ plants, and sequenced. In some cases, the use of a nested primer for amplicon sequencing instead of the forward or reverse PCR primer (Table 2) improved the quality of the sequence trace files used for SNP scoring. At this stage, the number of $F_{1}$ individuals, of which amplicons were sequenced was limited to 46 for practical reasons (half of a 96-well plate). Between one and fifteen segregating SNPs were scored per amplicon, amounting to 96 scored SNP markers in total (Table 2). Three segregating InDels were also evaluated. Most SNPs have been identified previously in the parental genotypes SR5 and SR6 (Rickert et al. 2003, https://www.gabi. rzpd.de/projects/Pomamo/). However, few new SNPs were also recorded. SNPs and InDels were tested for significant deviation from equal distribution between the two groups of highly resistant and susceptible genotypes by the $\chi^{2}$ test. Seven SNP markers deviated significantly $(P<0.01)$ from equal distribution (Table 2 ), indicating linkage to G. pallida QRL. All seven significant SNPs were located in the amplicons generated from three BAC insertion ends that are part of a local physical map on potato chromosome $\mathrm{V}$ in the interval between marker loci GP21 and GP179, which includes the $R 1$ gene for resistance to Phytophthora infestans (Ballvora et al. 2002, Ballvora et al. manuscript in preparation). The position of the $250 \mathrm{kbp}$ contig within the GP21-GP179 interval, the physical distances between the amplicons and the positions of the significant SNPs are shown in Fig. 1.

The seven SNP markers linked to a G. pallida QRL fell into two groups of tightly linked or cosegregating SNPs. The first group included three SNP markers: snp212 in amplicon BA87d17t3, snp139 and snp274 both in amplicon BA213c14t7. The second group consisted of four SNP markers: snp336 in amplicon BA76o11t3, snp152, snp236 and snp287 in amplicon BA213c14t7. A genetic model based on three different haplotypes $a, b$ and $c$ (Table 3 ) best explained the observed SNP genotype classes of the seven significant SNP markers in parents SR5 and SR6, and in 43 F1 hybrids (amplicon sequencing of one susceptible genotype consistently failed). 268 (91\%) of 294
Fig. 1 Positions of the seven SNP markers linked to the major QTL for resistance to $G$. pallida on the partial physical map in the interval GP21-GP179 on potato chromosome $\mathrm{V}$

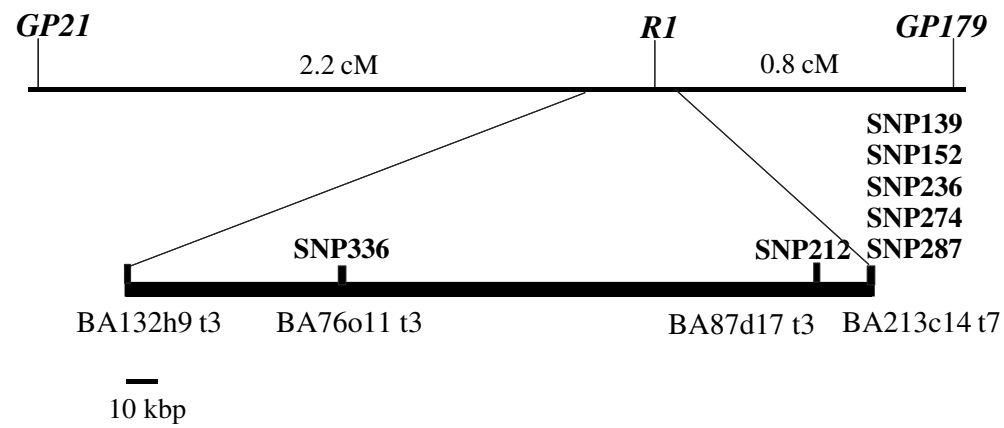


Table 3 Haplotype model deduced from the observed segregation of seven SNP markers linked to QTL for nematode resistance on chromosome V in the SR-Gpa family. Haplotype specific nucleotides are shown in bold letters

\begin{tabular}{llllllll}
\hline Haplotype & BA76o11t3 & BA87d17t3 & \multicolumn{2}{l}{ BA213c14t7 } & & \\
\cline { 3 - 7 } & snp336 & snp212 & snp287 & snp274 & snp236 & snp152 & snp139 \\
\hline$a$ & $\mathrm{C}$ & $\mathrm{C}$ & $\mathrm{T}$ & $\mathrm{A}$ & $\mathrm{C}$ & $\mathrm{T}$ & $\mathrm{G}$ \\
$b$ & $\mathbf{G}$ & $\mathrm{C}$ & $\mathbf{C}$ & $\mathrm{A}$ & $\mathbf{T}$ & $\mathbf{A}$ & $\mathrm{G}$ \\
$c$ & $\mathrm{C}$ & $\mathbf{T}$ & $\mathrm{T}$ & $\mathbf{T}$ & $\mathrm{C}$ & $\mathrm{T}$ & $\mathbf{A}$ \\
\hline
\end{tabular}

SNP scores (7 SNPs scored in 43 genotypes with few missing data) were in agreement with this haplotype model. The remaining scores (9\%) showed a discrepancy with the model, most likely resulting from ambiguous scores of the allele dosage. According to the model, the resistant parent SR6 was duplex for haplotypes $a$ and $c$ (aacc) and the susceptible parent SR5 was duplex for haplotypes $a$ and $b(a a b b)$. When assuming tetrasomic inheritance and random formation of $2 \mathrm{n}$ gametes in both parents, nine genotype classes are expected in the $F_{1}$ progeny in the frequencies shown in Table 4. Only five genotype classes were actually observed in the 43 examined $F_{1}$ individuals, of which four deviated significantly from the expected numbers (Table 4). The genotype class expected to be the most frequent $(a a b c)$ was completely absent in the progeny. Under the alternative hypothesis of disomic inheritance, four genotype classes with equal frequency are expected in $F_{1}$. In fact, three of the five observed genotype classes fitted the model of disomic inheritance, whereas the forth expected class $(b b c c)$ was not observed and the observed classes $a a a c$ and $a b b c$ were not expected (Table 4). The resistant parent SR6 and all 22 highly resistant $F_{1}$ individuals carried haplotype $c$ either in duplex or simplex condition. With the exception of one individual, all susceptible $F_{1}$ genotypes lacked haplotype $c$, indicating strong linkage between haplotype $c$ and a nematode resistance allele descending from SR6 (Table 4). Haplotype $b$ descending from the susceptible parent SR5 was more frequent in susceptible (13) than in resistant F1 individuals (9). Haplotype $b$ was therefore linked to a susceptibility allele. Nine of the ten individuals having both haplotypes $c$ and $b$ were highly resistant, indicating that the nematode resistance allele linked to haplotype $c$ was mostly dominant (Table 4).
A PCR assay was developed to detect specifically haplotype $c$, based on the SNP marker BA87d17t3-snp212, which had the haplotype $c$ specific allele $T$ (Table 3 ) and on snp444 $(T / C)$ in the same amplicon (Table 2). Snp444 was arbitrarily chosen for its physical distance from snp212, allowing the generation of a PCR product of suitable length. Only the primer combination specific for snp212-T/snp444-G amplified a $274 \mathrm{bp}$ fragment in the resistant parent SR6, in all 30 highly resistant $F_{1}$ individuals selected and in the single, susceptible individual having haplotype $c$ (Fig. 2). The susceptible parent SR5 and 29 susceptible $F_{1}$ individuals were negative for the haplotype $c$ specific PCR product, which is subsequently referred to as the HC marker.

Thirty four varieties with resistance to $G$. pallida pathotypes $\mathrm{Pa} 2$ or $\mathrm{Pa} 2 / \mathrm{Pa} 3$ according to passport data, the differential $S$. vernei clone 6233-3 (Pa2) (Ross 1986) and AM78.3778 (Pa2/3) (Rouppe van der Voort et al.1998) and 22 susceptible varieties as control group were tested for presence of the HC marker. In addition, the 56 varieties were scored for the haplotype $c$ specific SNP markers BA213c14t7-snp139 and snp274 by amplicon sequencing (Table 1). With the exception of cvs 'Avano' and 'Karakter', all varieties with high resistance to G. pallida pathotype $\mathrm{Pa} 2 / 3$ and clone AM78.3778 were HC positive, whereas the six varieties with resistance to pathotype $\mathrm{Pa} 2$ only, the $S$. vernei clone 62-33-3 and all susceptible varieties were $\mathrm{HC}$ negative (Table 1). From five varieties with reported intermediate or partial resistance to G. pallida (Amado, Kantara, Kardent, Katinka and Pallina) two were HC positive and three were negative (Table 1 ). These data indicated that the HC marker was highly diagnostic for the presence of an allele that confers high levels of resistance to G. pallida pathotype Pa2/3. The haplotype $c$ specific allele $T$ of 


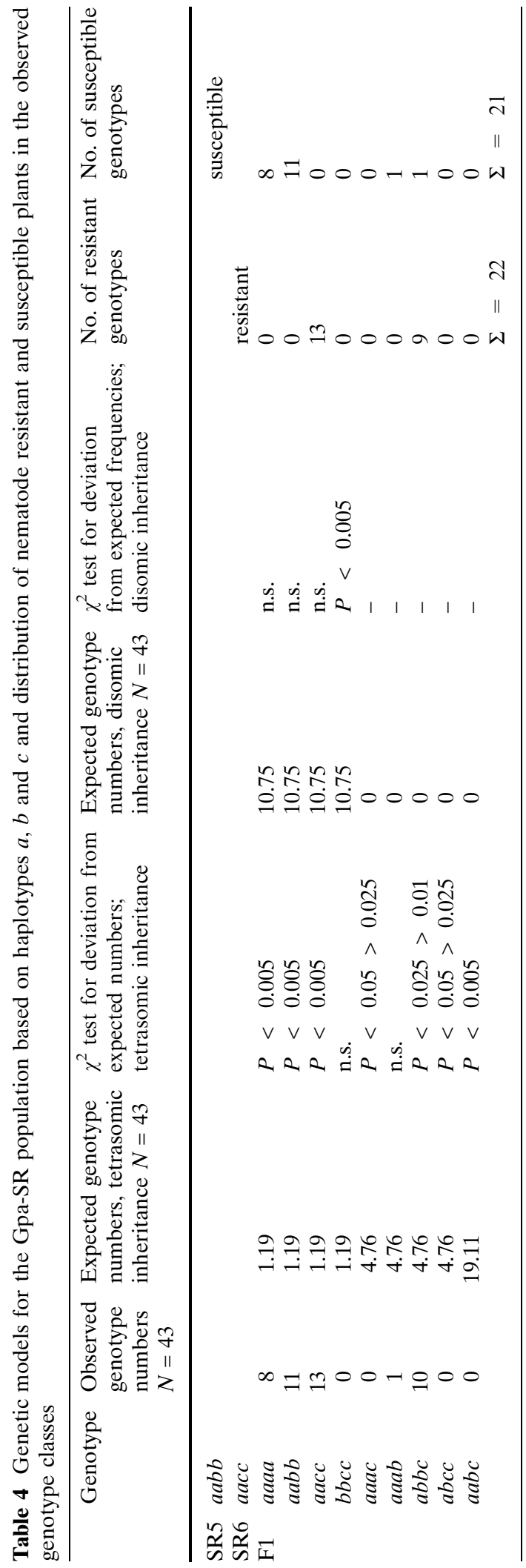

snp274 (Table 3) was in nearly complete linkage disequilibrium with the $\mathrm{HC}$ marker, the only exceptions being cvs 'Avano' and 'Festien' (Table 1). Based on the dosage of snp274 allele $T$, the $G$. pallida resistant varieties were mostly duplex, triplex or even quadruplex for the resistance allele. In contrast, the haplotype $c$ specific allele $A$ of snp139 (Table 3 ) was less diagnostic, as it occurred in all varieties with resistance to $G$. pallida pathotype $\mathrm{Pa} 2 / 3$, but also in 5 susceptible varieties and in cv 'Feska' being resistant only to pathotype $\mathrm{Pa} 2$ (Table 1).

A DNA collection of 31 Solanum species was screened for presence of the HC marker. HC was exclusively detected in accessions of $S$. vernei (data not shown), identifying $S$. vernei as the most likely source of the resistance to $G$. pallida pathotype $\mathrm{Pa} 2 / 3$.

The set of potato varieties and $S$. vernei differential clones was tested for presence or absence of the diagnostic SPUD1636 marker, which is linked to a major QRL to G. pallida in the same region on potato chromosome V (Bryan et al. 2002). All susceptible varieties tested lacked the SPUD1636 marker, but SPUD1636 was present in only 12 of the 22 highly resistant varieties, in 8 of the 12 varieties with incomplete resistance and in both clones $S$. vernei 62-33-3 and AM78.3778 (Table 1). SPUD1636 was therefore less diagnostic for high resistance to $G$. pallida pathotype $\mathrm{Pa} 2 / 3$ than the HC marker, BA213c14t7 snp139 and snp274.

\section{Discussion}

SNP genotyping by sequence analysis of heterozygous amplicons

The cultivated, tetraploid potato is highly polymorphic and heterozygous at the DNA sequence level, allowing parallel and quantitative scoring of several SNP markers in sequence trace files of single amplicons (Rickert et al. 2003). This notion was confirmed when genotyping the Gpa-SR family for 96 SNP markers in 15 amplicons. Most, but not all SNP positions and SNP allele dosages were reproducible when comparing the SNP's segregating in the Gpa-SR family with the SNP's scored in the genotype panel of Rickert et al. 
Fig. 2 Distribution of the HC marker in the highly nematode resistant (top) and susceptible (bottom) subpopulations selected from the SR-Gpa family

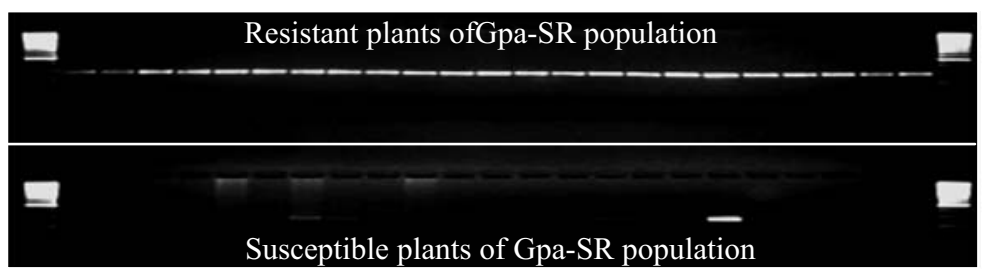

(2003), which included the parents SR5 and SR6. Some new SNP's were also detected in the GpaSR family. Moreover, genetic modeling uncovered discrepancies between $9 \%$ of the individual SNP scores and the genetic model. These inconsistencies and discrepancies point to scoring errors, particularly of the SNP allele dosage. The peak height in the sequence trace files used as measure for the allele dosage can be influenced differently for different nucleotides by the surrounding sequence context. Unequal allele amplification in heterozygous genotypes can also lead to erroneous assessment of the allele dosage. Generating very high quality sequences from locus specific, uniform amplicons can minimize, but does not eliminate completely these problems. The sequence quality of some amplicons could be improved by using for sequencing a nested primer located in an apparently 'SNP free' region of the sequence. The locus specificity of the amplicons depends on the redundancy of the genomic sequence and had to be determined experimentally case by case.

\section{Distorted segregation}

The pedigree information of the Gpa-SR family made possible to identify three haplotypes $a, b$ and $c$, based on the observed segregation patterns of seven SNP markers significantly linked to a major QTL for resistance to $G$. pallida. The haplotypes were used to assign a genotype to each parent and to $43 \mathrm{~F} 1$ individuals. The observed genotype classes and the observed number of individuals in each genotype class fitted neither the model of tetrasomic nor disomic inheritance. Genotype classes expected for either model of inheritance were completely absent in the progeny, and frequencies of observed genotype classes strongly deviated from expectation. These distorted frequencies of genotype classes can be the result of an intermediate mode of inheritance with preferential pairing of homologous chromosomes due to structural differences between different haplotypes and/or of the strong selection applied for highly resistant versus highly susceptible individuals. The absence of certain genotype classes (e. g. $a a b c$ in tetrasomic inheritance or $b b c c$ in disomic inheritance) implicates incomplete nematode resistance of these classes. This may indicate interactions between different alleles at the linked nematode resistance locus and incomplete dominance of the resistance allele linked to haplotype $c$ in certain allele constellations. This observation is compatible with the detection of haplotype $c$ in some varieties with incomplete resistance to G. pallida pathotype $\mathrm{Pa} 2 / 3$.

Position of the nematode resistance gene linked to SNP haplotype $c$

Knowledge on the distribution of loci for pathogen resistance in the potato genome (Gebhardt and Valkonen 2001, https://www.gabi.rzpd.de/ projects/Pomamo/) facilitated the mapping of the unknown nematode resistance locus in the GpaSR population by selective genotyping with SNP markers. Probing only twelve regions on ten potato chromosomes was sufficient to map the resistance locus. All SNP markers that showed significant linkage with resistance were located in the interval GP21-GP179 on potato chromosome $\mathrm{V}$, in a physical region containing a family of NBLRR type genes, one member of which has been functionally characterized as the $R 1$ gene for resistance to late blight (Ballvora et al. 2002; Kuang et al. 2005), whereas no function is known for the other members of the family. One or more members of the $R 1$ gene family are good positional candidates for being the molecular basis also of the genes for nematode resistance located 
in this region, similarly as has been found for genes $R x 1$ for resistance to Potato Virus $X$ (PVX) and Gpa2 for resistance to G. pallida pathotype $\mathrm{Pa} 2$, which are both highly homologous members of a clustered NB-LRR type gene family on potato chromosome XII (van der Vossen et al. 2000). To the same genomic region on potato chromosome $\mathrm{V}$ as identified in this paper, major QTL for resistance to G. pallida and G. rostochiensis have been mapped previously, which originated from the wild species $S$. spegazzinii, $S$. vernei, $S$. sparsipilum and possibly others (Kreike et al. 1994; Rouppe van der Voort et al. 1998, 2000; Bryan et al. 2002; Caromel et al. 2003; 2005). S. vernei is the most likely source of the resistance allele present in breeding clone SR6 and in most varieties with high resistance to $G$. pallida pathotype $\mathrm{Pa} 2 / 3$. This was shown when a panel of 31 Solanum species was screened for presence of the haplotype $c$ specific $\mathrm{HC}$ marker and only $S$. vernei accessions were found to be HC positive. The major locus for resistance to $G$. pallida detected in the Gpa-SR population is therefore identical or very similar to the major cyst nematode QRL Grp1 and Gpa5 described previously (Rouppe van der Voort et al.1998, 2000). The resistance allele of $S$. vernei detected by the $\mathrm{HC}$ marker on potato chromosome $\mathrm{V}$ is named $R G p 5$-vrnHC.

The diagnostic value of the HC nematode resistance marker

The HC marker is the most diagnostic DNA marker currently available for potato resistance to G. pallida. It was detected in almost all tested German or Dutch potato varieties with high resistance levels to G. pallida pathotype $\mathrm{Pa} 2 / 3$. This indicates that the allele RGp5-vrnHC has been widely used in resistance breeding at least in Germany and the Netherlands. The origin of this allele is unknown, as several $S$. vernei clones have been described as resistance sources (Ross 1986), which are not available any more for testing. At this point, we can only exclude as source clone $S$. vernei 62-33-3, which is resistant to G. pallida pathotype $\mathrm{Pa} 2$ (Ross 1986) and was accordingly $\mathrm{HC}$ negative. However, S. vernei accessions available in germ plasm collections can now easily be screened by PCR with the HC marker. HC positive plants may also be highly resistant to G. pallida. We are currently testing whether the $\mathrm{HC}$ marker retains its diagnostic value for resistance to G. pallida pathotype $\mathrm{Pa} 2 /$ 3 in different accessions of $S$. vernei. Information on presence or absence of the HC marker in parental clones or advanced breeding material will be useful in breeding programs. Knowing the allele dosage provides additional information on the expected transmission frequency of the resistance. The allele dosage cannot be assessed by the qualitative PCR test for the HC marker. However, other high throughput SNP detection methods such as pyrosequencing are suitable for allele quantification (Rickert et al. 2002) and could be applied to the most diagnostic SNPs BA87d17t3-snp212 and BA213c14t7-snp274. The HC marker can also be helpful for discriminating among different field populations of G. pallida, by using $\mathrm{HC}$ positive and $\mathrm{HC}$ negative genotypes as genetically precisely characterized differentials.

There are a few limitations to the predictive power of the HC marker. Variety 'Avano', which is highly resistant to G. pallida $\mathrm{Pa} 2 / 3$ according to passport data, was $\mathrm{HC}$ negative. In this case, a recombination event might have separated the HC marker from the resistance allele RGp5vrnHC, or 'Avano' has a different source of resistance, or the resistance assessment might be ambiguous. On the other hand, some varieties with incomplete resistance such as 'Amado' and 'Kardent' were HC positive. This can result from incomplete dominance of the RGp5-vrnHC allele in certain genetic backgrounds or from resistance assessment using $G$. pallida populations, which partially overcome the resistance allele $R G p 5$ vrnHC.

Acknowledgements The authors gratefully acknowledge the funding of this work under the GABI program (Genome analysis in the biological system of plants) by BMBF (Bundesministerium für Bildung und Forschung), Project No 0312290 CONQUEST (Genes CONtrolling QUantitativE traits of Solanum Tuberosum). Part of this work was carried out in the department of plant breeding research and yield physiology, headed by Francesco Salamini, and in the department of plant breeding research and genetics, headed by Maarten Koornneef. 


\section{References}

Ballvora A, Ercolano MR, Weiß J, Meksem K, Bormann C, Oberhagemann P, Salamini F, Gebhardt C (2002) The $R 1$ gene for potato resistance to late blight (Phytophthora infestans) belongs to the leucine zipper/NBS/LRR class of plant resistance genes. Plant J 30:361-371

Behringer P (1969) Feststellung zystenbildender Nematoden mit dem Biotest im Vierkammergefäß Mitt. Biol Bundesanst 136:5

Bormann CA, Rickert AM, Castillo Ruiz RA, Paal J, Lübeck J, Strahwald J, Buhr K, Gebhardt C (2004) Tagging quantitative trait loci for maturity-corrected late blight resistance in tetraploid potato with PCRbased candidate gene markers. Mol Plant-Microbe Interac 17:1126-1138

Bradshaw JE, Hackett CA, Meyer RC, Milbourne D, McNicol JW, Phillips MS, Waugh R (1998) Identification of AFLP and SSR markers associated with quantitative resistance to Globodera pallida (Stone) in tetraploid potato (Solanum tuberosum ssp. tuberosum) with a view to marker-assisted selection. Theor Appl Genet 97:202-210

Bryan G, McLean K, Pande B, Purvis A, Hackett CA, Bradshaw JE, Waugh R (2004) Genetical dissection of $\mathrm{H} 3$-mediated polygenic PCN resistance in a heterozygous autotetraploid potato population. Mol Breed 14:105-116

Bryan GJ, McLean K, Bradshaw JE, De Jong WS, Phillips M, Castelli L, Waugh R (2002) Mapping QTLs for resistance to the cyst nematode Globodera pallida derived from the wild potato species Solanum vernei. Theor Appl Genet 105:68-77

Caromel B, Mugniéry D, Lefebvre V, Andrzejewski S, Ellissèche D, Kerlan MC, Rousselle P, RousselleBourgeois F (2003) Mapping QTLs for resistance against Globodera pallida (Stone) $\mathrm{Pa} 2 / 3$ in a diploid potato progeny originating from Solanum spegazzinii. Theor Appl Genet 106:1517-1523

Caromel B, Mugniéry D, Kerlan MC, Andrzejewski S, Palloix A, Ellissèche D, Rousselle-Bourgeois F, Lefebvre V (2005) Resistance quantitative trait loci originating from Solanum sparsipilum act independently on the sex ratio of Globodera pallida and together for developing a necrotic reaction. Mol Plant- Microbe Interact 18:1186-1194

Evans K, Trudgill DL (1992) Pest aspects of potato production. Part 1. The nematode pests of potato. In: Harris P (ed), The Potato Crop 2nd edn. Chapman and Hall, London, pp 438-475

Gebhardt C, Valkonen JPT (2001) Organization of genes controlling disease resistance in the potato genome. Annu Rev Phytopathol 39:79-102

Gebhardt C, Ballvora A, Walkemeier B, Oberhagemann P, Schüler K (2004) Assessing genetic potential in germ plasm collections of crop plants by marker-trait association: a case study for potatoes with quantitative variation of resistance to late blight and maturity type. Mol Breed 13:93-102
Kort J, Ross H, Rumpenhorst H, Stone AR (1977) An international scheme for identifying and classifying pathotypes of potato cyst nematodes Globodera rostochiensis and G. pallida. Nematologica 23:333-339

Kuang H, Wei F, Marano MR, Wirtz U, Wang X, Liu J, Shum WP, Zaborsky J, Tallon LJ, Rensink W, Lobst S, Zhang P, Tornquist C-E, Tek A, Bamberg J, Helgeson J, Fry W, You F, Luo M-C, Jiang J, Buell CR, Baker B (2005) The $R 1$ resistance gene cluster contains three groups of independently evolving, type I $R 1$ homologues and shows substantial structural variation among haplotypes of Solanum demissum. Plant J 44:37-51

Kreike CM, de Koning JRA, Vinke JH, van Ooijen JW, Stiekema WJ (1994) Quantitatively-inherited resistance to Globodera pallida is dominated by one major locus in Solanum spegazzinii. Theor Appl Genet 88:764-769

Lo YM, Patel P, Newton CR, Markham AF, Fleming KA, Wainscoat JS (1991) Direct haplotype determination by double ARMS: specificity, sensitivity and genetic applications. Nucleic Acids Res 19:3561-3567

Okimoto R, Dodgston JB (1996) Improved PCR amplification of multiple specific alleles (PAMSA) using internally mismatched primers. Biotechiques 21:2026

Phillips MS (1994) Inheritance of resistance to nematodes. In: Bradshaw JE, Mackay GR (eds), Potato Genetics. CAB International, Wallingford, pp 319-337

Rickert AM, Kim JH, Meyer S, Nagel A, Ballvora A, Oefner PJ, Gebhardt C (2003) First-generation SNP/ InDel markers tagging loci for pathogen resistance in the potato genome. Plant Biotechnol J 1:399-410

Rickert AM, Premstaller A, Gebhardt C, Oefner PJ (2002) Genotyping of SNPs in a polyploid genome by pyrosequencing. Biotechniques 32:592-593, 596-598, 600

Ross H (1986) Potato breeding - problems and perspectives. Advances in Plant Breeding, Supplement 13 to Journal of Plant Breeding, Paul Parey, Berlin, Hamburg, pp 75-82

Rouppe van der Voort J, van der Vossen E, Bakker E, Overmars H, van Zandvoort P, Hutten R, KleinLankhorst R, Bakker J (1998) A QTL for broadspectrum resistance to cyst nematode species (Globodera spp.) maps to a resistance gene cluster in potato. Theor Appl Genet 96:654-661

Rouppe van der Voort J, van der Vossen E, Bakker E, Overmars H, van Zandvoort P, Hutten R, KleinLankhorst R, Bakker J (2000) Two additive QTLs conferring broad-spectrum resistance in potato to Globodera pallida are localized on resistance gene clusters. Theor Appl Genet 101:1222-1230

Sarkar G, Sommer SS (1991) Haplotyping by double PCR amplification of specific alleles. Biotechniques 10:436440

Van der Vossen EAG, Rouppe van der Voort JNAM, Kanyuka K, Bendahmane A, Sandbrink H, Baulcombe DC, Bakker J, Stiekema WJ, Klein-Lankhorst RM (2000) Homologues of a single resistance-gene cluster in potato confer resistance to distinct pathogens: a virus and a nematode. Plant J 23:567-576 